\title{
Near infrared spectroscopy determination of sucrose, glucose and fructose in sweet sorghum juice
}

\author{
Maria Lúcia F. Simeone ${ }^{\mathrm{a}, *}$, Rafael A.C. Parrella a , Robert E. Schaffert ${ }^{\text {a }}$, Cynthia M.B. Damasceno ${ }^{\text {a }}$, \\ Michelle C.B. Leal ${ }^{\mathrm{a}}$, Celio Pasquini ${ }^{\mathrm{b}}$ \\ a Embrapa Milho e Sorgo, MG 424, km 45, 35701-970 Sete Lagoas, MG, Brazil \\ b University of Campinas, Chemistry Institute, C. P. 6154, 13083-970 Campinas, SP, Brazil
}

\section{A R T I C L E I N F O}

Article history:

Received 20 October 2016

Received in revised form 3 April 2017

Accepted 28 May 2017

Available online 29 May 2017

\section{Keywords:}

Biofuel

Multivariate calibration

Bioenergy crop

Partial least squares regression

\begin{abstract}
A B S T R A C T
Sweet sorghum is a very robust crop which has the potential to be used in ethanol production due to its high fermentable sugar content present in its stem juice, very similar to sugarcane. Therefore, for breeding purposes it is relevant to analyze sugar composition in the juice to characterize sweet sorghum genotypes and their period of industrial utilization within different environments for maximum ethanol yield. In this work we developed a rapid, low cost and efficient method to determine the profile of sugars (sucrose, glucose and fructose) in sorghum juice by near infrared spectroscopy and partial least square regression, and validation of the method was performed according to the high-performance liquid chromatography method. Developed models provided root mean square error of prediction of 4,1 and $0.6 \mathrm{mg} \cdot \mathrm{mL}^{-1}$ and ratio performance deviations of 8,5 and 5 for sucrose, glucose and fructose, respectively. Relative standard deviations of three sweet sorghum juice samples were reported with content variation (low, medium and high) $0.2,0.3,0.8 \%$ for sucrose; $1,2,2 \%$ for glucose; $1,2,3 \%$ for fructose. Sugar profile is an asset for crop breeders to take decisions for the development of more productive cultivars and higher sugar content.
\end{abstract}

(C) 2017 Elsevier B.V. All rights reserved.

\section{Introduction}

Sweet sorghum is one of the most promising alternative crops to sugarcane for ethanol production due to the presence of sweet juice in its stem [1].

Sugar content in sweet sorghum juice varies between 14 and $23 \%$ Brix and may be extracted by protocols similar to those used for sugarcane [2]. The juice from the fresh stem contains sucrose, glucose and fructose, with sucrose being the main sugar $[3,4]$.

One of the measures undertaken by the sugar industry to assess sweet sorghum quality is the determination of the contents of soluble solids (Brix) of the juice extracted. However, the Brix is an indirect measure that relates the soluble solids dissolved in water based on refractive index changes. It is a measure widely used in the technological qualification of sugarcane juice [5], fruit juice [6] without specifying the sugar present. Brix in sweet sorghum samples has been strongly correlated with sucrose content, albeit not correlated with glucose and fructose [7].

Since the sugar extracted from sweet sorghum is a function of biomass yield, fiber content and juice quality, it is important to know the

\footnotetext{
* Corresponding author at: Embrapa Maize and Sorghum, Rod. MG 424, Km 45, C. P. 285, Sete Lagoas, MG 35 701-970, Brazil.

E-mail address: marialucia.simeone@embrapa.br (M.L.F. Simeone).
}

composition of the sugars in sorghum juice to better qualify the sweet sorghum genotypes and their period of industrial utilization (PIU) in different environments to provide maximum yield of ethanol during the fermentation process [2]. PIU should be the longest possible, with a minimum threshold of 30 days. In fact, PIU comprises the period in which the cultivar may remain in the field maintaining productivity and quality at optimal levels, according to the minimum standards established to ensure the viability of the crop until it is harvested and processed by the ethanol industry.

Chromatographic techniques, such as high performance liquid chromatography (HPLC) [8], ion chromatography (IC) [9], gas chromatography (GC) [10] or enzymatic methods [11], are commonly used to determine the chemical composition of sugars in sorghum juice.

However, all these techniques, coupled to several chemicals and inputs needed for sample preparation allow only a few analyses per day.

The Embrapa Sorghum Breeding Program requires a great number of sugar content analyses of sweet sorghum juice during the harvest period. The method we stablished in this work allowed a faster and low-cost alternative to the HPLC method to detect hybrids with high sugar yield potential during their PIU. The method employs near infrared spectroscopy (NIR) associated to the development of multivariate chemometric regression models. PLS regression is a multivariate method and uses information of the NIR spectrum to establish the calibration equation. NIR 
Table 1

Sucrose, glucose and fructose contents as determined by HPLC from 160 samples of sweet sorghum juice.

\begin{tabular}{llll}
\hline Component & Sucrose & Glucose & Fructose \\
\hline Minimum & 26.50 & 6.60 & 4.21 \\
Maximum & 169.52 & 36.16 & 17.5 \\
Mean & 89.40 & 17.58 & 9.97 \\
Standard deviation & 3 & 5 & 2 \\
\hline
\end{tabular}

Units: $\mathrm{mg} \mathrm{mL}^{-1}$.

region contains information on the relative proportions of $\mathrm{C}-\mathrm{H}, \mathrm{N}-\mathrm{H}$ and $\mathrm{O}-\mathrm{H}$ bands which are the primary structural components or organic molecules [12].

This approach has been widely used in numerous agricultural and food products [13] and offers decisive advantages over traditional methods, such as little sample handling, no chemicals, high precision and accuracy, inexpensiveness and faster results [12].

The evaluation of sugar quality by near infrared spectroscopy has been reported in the literature for fruit juice [14], sugar beet [15], sugarcane [16] and sweet sorghum in dry samples [17,18]. Chen et al. [17] extracted sucrose and glucose from dry sorghum stalks using distilled water and autoclave at $121{ }^{\circ} \mathrm{C}$ for $15 \mathrm{~min}$. Mid-infrared spectroscopy was used to predict sucrose, glucose and fructose contents in juice samples of sweet sorghum [4].

This work aimed at developing a multivariate calibration-based method using near infrared transflectance spectroscopy as a source of analytical information to determine sucrose, glucose and fructose contents in sweet sorghum juice with the minimal pretreatment of samples for high-throughput screening phenotyping.

\section{Materials and methods}

\subsection{Preparation of samples}

The experiment was conducted in the field experimental area of Embrapa Maize and Sorghum, in Sete Lagoas $\left(19^{\circ} 28^{\prime} \mathrm{S}, 44^{\circ} 15^{\prime} 08^{\prime \prime} \mathrm{W}\right)$,
MG, Brazil, using cultivars of Embrapa's sweet sorghum breeding program.

One hundred sixty juice samples, from eight genotypes of sweet sorghum (BRS 508, BRS 509, BRS 511, CMSXS643, CMSXS646, CMSXS647, CV 198, CV 568 with similar flowering patterns were harvested, at different stages of maturation, 72 days after sowing with an interval of seven days approximately. The samples were collected during 2015 and 2016

Normal cultural practices were maintained to conduct the experiment, following May et al. [19].

\subsection{Sugar analysis}

Stalk panicles were removed and eight stalks were crushed in a forage chopper machine (Irbi, Araçatuba SP Brazil). Further, $500 \mathrm{~g}$ of the material were taken to the hydraulic press (Hidraseme, Ribeirão Preto SP Brazil) for 1 min with minimal constant pressure of $250 \mathrm{kgf} \cdot \mathrm{cm}^{-2}$. An $80 \mathrm{~mL}$ aliquot of juice extracted from each sample was stored in a polyethylene vial and frozen at $-4{ }^{\circ} \mathrm{C}$ for later analysis, totaling 160 samples. Sucrose, glucose and fructose contents were analyzed by HPLC as follows: sorghum juice samples were thawed at room temperature and $3 \mathrm{~mL}$ of each sample were diluted 15 times with deionized water. The samples were then shaken at $45 \mathrm{rpm}$ for $15 \mathrm{~min}$ and centrifuged at $3000 \mathrm{rpm}$ for $15 \mathrm{~min}$. Samples were filtered through a C18 cartridge, previously conditioned with $2 \mathrm{~mL}$ acetonitrile and $2 \mathrm{~mL}$ deionized water. After this process, $2 \mathrm{~mL}$ of the solution were filtered with $0.45 \mu \mathrm{m}$ membrane filters (PTFE) and analyzed by HPLC (2695 Alliance Waters, Milford, MA, USA) using a Phenomenex column (RCM-Ca). The mobile phase used was ultrapure water flux $0.6 \mathrm{~mL} \mathrm{~min}^{-1}$, column temperature $65{ }^{\circ} \mathrm{C}$. The detector was the Refractive Index (Milford MA, USA) working at $40{ }^{\circ} \mathrm{C}$. Analytical curves were produced by using sucrose, D-glucose and D-fructose as standards (Sigma-Aldrich) with $99.5 \%$ purity, respectively. Sucrose, glucose and fructose in the samples were detected by comparison to standard retention time. Three calibration curves $\left(R^{2} \geq 0.999\right)$ were established for sucrose, glucose,

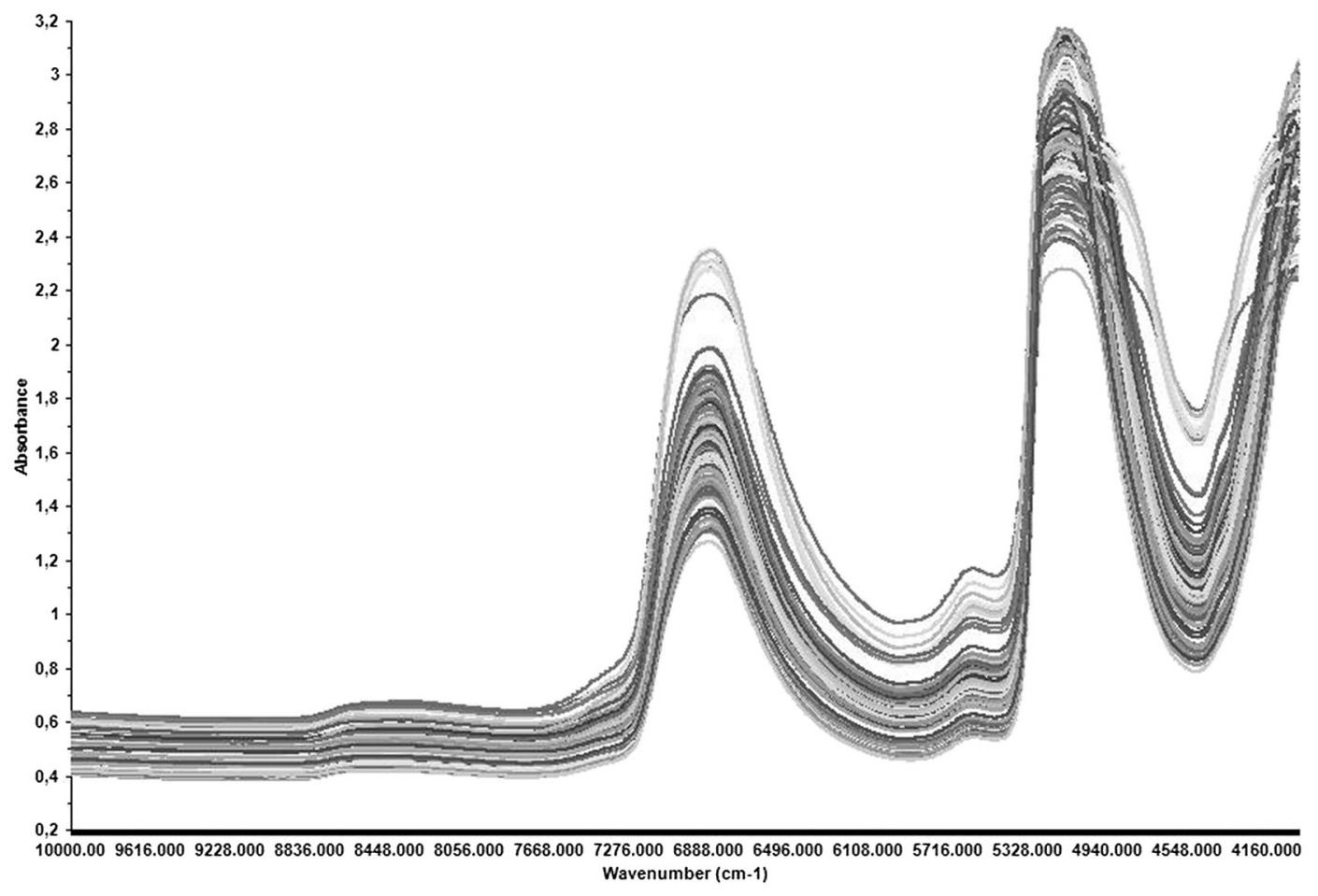

Fig. 1. Set of raw NIR spectra of 160 sorghum juice samples. 
Table 2

Summary of statistical indicators for calibration and validation of sucrose, glucose and fructose content $\left(\mathrm{mg} \mathrm{mL}^{-1}\right)$ in sweet sorghum juice determinate by the optimized NIR based PLS models.

\begin{tabular}{llll}
\hline Component & Sucrose & Glucose & Fructose \\
\hline Calibration & & & \\
Number of samples & 100 & 100 & 100 \\
LV $^{\mathrm{a}}$ & 5 & 8 & 7 \\
RMSEC $^{\mathrm{b}}$ & 3 & 0.8 & 0.5 \\
$\mathrm{R}^{2 \mathrm{c}}$ & 0.99 & 0.97 & 0.95 \\
$\mathrm{RPD}^{\mathrm{d}}$ & 9 & 6 & 5 \\
Validation & & & \\
Number of samples & 60 & 60 & 60 \\
RMSECV & 4 & 1 & 0.6 \\
RMSEP $^{\mathrm{f}}$ & 4 & 1 & 0.6 \\
Bias $^{2 \mathrm{c}}$ & 0.89 & -0.21 & -0.01 \\
RPD $^{\mathrm{d}}$ & 0.98 & 0.94 & 0.94 \\
RER $^{\mathrm{g}}$ & 8 & 5 & 5 \\
\hline
\end{tabular}

${ }^{\text {a }} \mathrm{LV}=$ latent variable.

b RMSEC = root mean square error of the calibration.

c $\mathrm{R}^{2}=$ determination coefficient.

d $\mathrm{RPD}=$ ratio performance deviation.

RMSECV $=$ root mean square error of cross-validation.

${ }^{f}$ RMSEP $=$ root mean square error of prediction.

g $\mathrm{RER}=$ range error ratio.

and fructose, respectively, from determinations at six different sugar concentrations.

\subsection{Near infrared spectra data calibration and validation}

Juice sweet sorghum samples $(50 \mathrm{~mL})$ were filtered in cotton and placed on a petri dish ( $100 \mathrm{~mm}$ in diameter) with a transflection accessory (total nominal optical path of $1.5 \mathrm{~mm}$ ) to collect NIR spectra with NIRFlex N-500 FT-NIR spectrometer (Flawil, Switzerland). The spectrometer was controlled and data were retrieved by NIRWare Operator software and handled with Unscrambler X® (version 10.3, CAMO Software Inc., Woodbridge NJ USA) software. The spectra were recorded in triplicate from 10,000 to $4000 \mathrm{~cm}^{-1}$ with $4 \mathrm{~cm}^{-1}$ steps, averaging 32 scans, at $25 \pm 2{ }^{\circ} \mathrm{C}$. HPLC analyses were performed after NIR measurement.

Prior to calibration, several preprocessing techniques, standard normal variate (SNV) and first-derivative Savitzky-Golay (SG-1), with 9 points on the right and on the left, were applied to the spectra to obtain the best calibration equation. Two sample sets were prepared for calibration and external validation applying the Kennard-Stone algorithm [21] to the values of the PLS scores of the samples.

The partial least square (PLS) method was used to provide a prediction eq. [20]. Model performance was assessed by the coefficient determination $\left(\mathrm{R}^{2}\right)$ of calibration and validation, root mean square error of calibration (RMSEC), (RMSECV, a full cross-validation) and prediction (RMSEP, for the external validation set). A full cross-validation following the random method was performed to determine the optimum number of factors for the model and to detect any outliers. Accuracy of the generated PLS models was attested by trueness and precision studies. Two other parameters, namely, ratio performance deviation (RPD) and range error ratio (RER), were used to evaluate the model's prediction capacity [22].

\section{Results and discussion}

Soluble sugars are major components of sweet sorghum juice, with a wide range of sucrose, glucose and fructose concentrations [23].
Current study characterized 160 samples of sweet sorghum juice by HPLC analysis during maturation curve period of sweet sorghum development.

We observed that sugar profiles changed according to sorghum's developmental stage and the genotype analyzed.

The overall average sugar content in sweet sorghum juice (Table 1) was $89.40 \mathrm{mg} \mathrm{mL}^{-1}$ sucrose, $17.58 \mathrm{mg} \mathrm{mL}^{-1}$ glucose and $9.97 \mathrm{mg} \mathrm{mL}^{-1}$ fructose. Juice from sweet sorghum genotypes exhibited total fermentable sugars ranging between 105.43 and $204.99 \mathrm{mg} \mathrm{mL}^{-1}$ and averaging $171.92 \mathrm{mg} \mathrm{mL}^{-1}$.

The raw spectra set in Fig. 1 show baseline offsets due to light scattering or refractive index variation due to concentration variation.

All NIR spectra showed that vibration bands from $\mathrm{O}-\mathrm{H}$ and $\mathrm{C}-\mathrm{H}$ groups were correlated with sugar components. While the structures of sugars are similar and they exhibit similar NIR absorption peaks, they may be probably differentiated by their absorption magnitude due to the different numbers of $\mathrm{O}-\mathrm{H}$ groups, and slight changes in
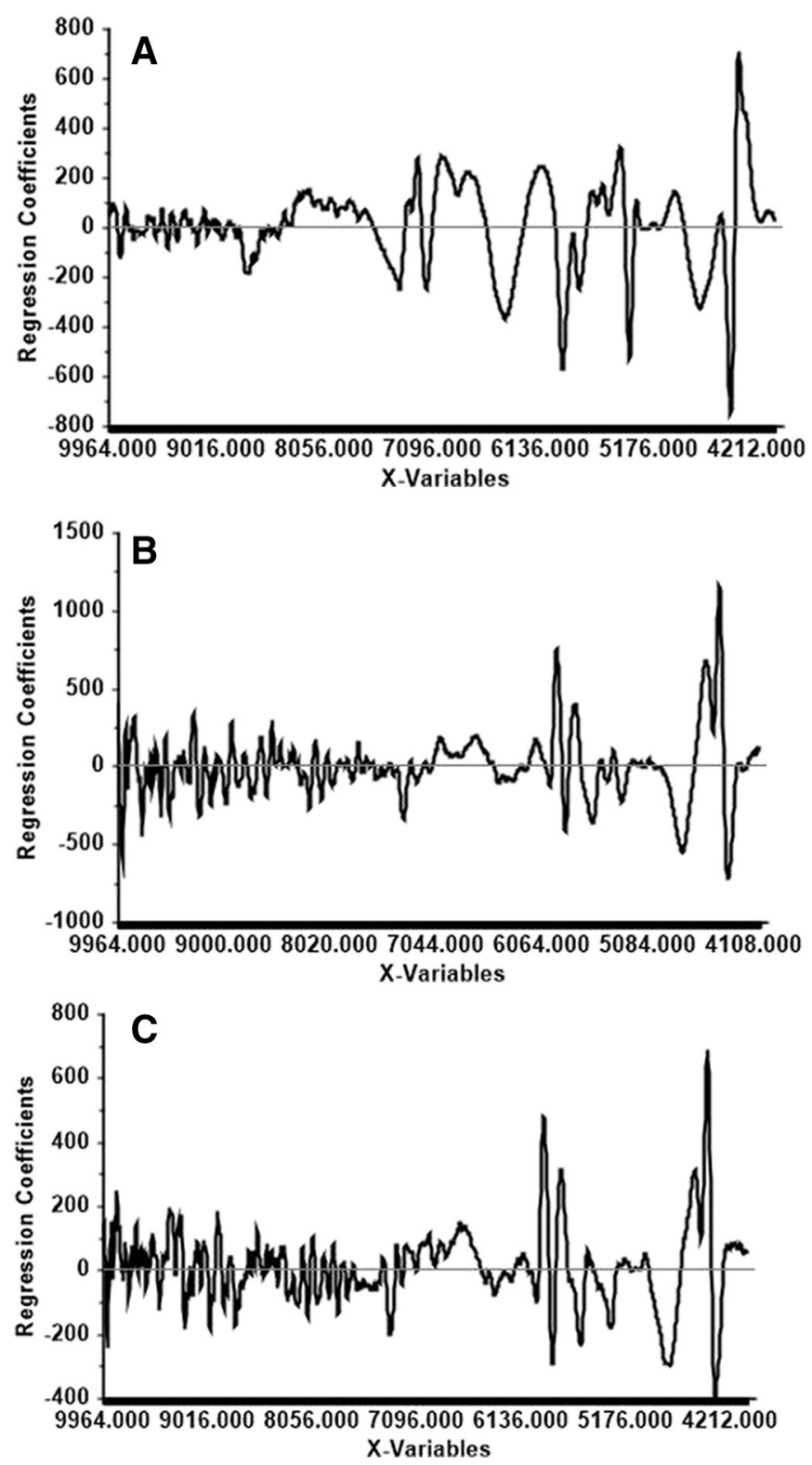

Fig. 2. Plots of regression coefficients for the sucrose, glucose and fructose PLS models. Sucrose (A), glucose (B) and fructose (C). 
the $\mathrm{O}-\mathrm{H}$ and $\mathrm{C}-\mathrm{H}$ absorption band positions caused by inter-molecular hydrogen bonds. The absorption bands due to $\mathrm{O}-\mathrm{H}$ and $\mathrm{C}-\mathrm{H}$ groups in sugars in which sucrose contains eight $\mathrm{O}-\mathrm{H}$ functional groups and glucose and fructose contain five groups each largely influence the spectral variation although they may still be differentiated [24]. Spectral ranges between 7200 and 6600, 6000 and 5500, 5400 and 4600 , and 4600 and $4000 \mathrm{~cm}^{-1}$ may be attributed to $\mathrm{O}-\mathrm{H}$ stretch first overtone, $\mathrm{C}-\mathrm{H}$ stretch first overtone, $\mathrm{O}-\mathrm{H}$ combination bands and $\mathrm{C}-\mathrm{H}$ combination band regions, respectively [25]. Strong peaks between 7400 and $6400 \mathrm{~cm}^{-1}$ and between 5400 and $4600 \mathrm{~cm}^{-1}$ are mainly related to the first overtone of $\mathrm{O}-\mathrm{H}$ stretching and $\mathrm{O}-\mathrm{H}$ combination bands of water, respectively and were not use to develop the PLS models. Spectral regions between 5800 and $5400 \mathrm{~cm}^{-1}$ and between 4600 and $4000 \mathrm{~cm}^{-1}$ are related to the first overtone of $\mathrm{C}-\mathrm{H}$ stretching and $\mathrm{C}-\mathrm{H}+\mathrm{C}-\mathrm{H}$ and $\mathrm{C}-\mathrm{H}+$ $\mathrm{C}-\mathrm{C}$ combination bands, respectively, both attributed to vibrations of the molecules of sugars [24,26]. Considering the absence of significant signals in this region between 10,000 and $7800 \mathrm{~cm}^{-1}$, it was deleted previously to the development of the models.

All NIR spectra collected were preprocessed with mean centering, whilst the presence of scattering and baseline deviations were corrected by SNV (standard normal variate) and first derivative with 9-point Savitzky-Golay (9 on the right, 9 on the left). Samples are divided into calibration $(\mathrm{n}=100)$ and validation $(\mathrm{n}=60)$ sets utilizing the Kennard-Stone algorithm [21]. Calibrations sets cover the widest range of sugar concentration (Table 2).
The preprocessed spectra (5800-5400 $\mathrm{cm}^{-1}$ and $4600-4000 \mathrm{~cm}^{-1}$ ) were submitted to PLS calibration to give the most accurate models for sucrose, glucose, and fructose content. RMSEC for calibration set, RMSECV a full cross-validation, RMSEP for prediction set and $\mathrm{R}^{2}$ were considered to evaluate results. RMSEC provides information about the adjustment of the model to calibration data.

Latent variables (LVs) can be used to reduce the dimensionality of data, and the optimal number of latent variables (LVs) was determined by the lowest value of predicted residual error sum of squares (PRESS) [27]. Consequently, the calibration optimal models were selected to high $\mathrm{R}^{2}$, and low RMSEC, RMSECV, RMSEP and bias [28].

Fig. 2 shows the regression coefficients for the models. The coefficients for sucrose, glucose and fructose present a great similarity among them. The highest variation was associated with frequencies in the 7800 $4000 \mathrm{~cm}^{-1}$ region. In general, coefficients associated with water vibrations are negative, while the coefficients associated with sugars are positive $[15,17]$. The information-rich region from 4600 to $4000 \mathrm{~cm}^{-1}$ can be ascribed to combinations of $\mathrm{O}-\mathrm{H}$ bend/hydrogen-bonded $\mathrm{O}-\mathrm{H}$ stretch $\left(4428 \mathrm{~cm}^{-1}\right), \mathrm{O}-\mathrm{H}$ stretch/C $-\mathrm{C}$ stretch $\left(4393 \mathrm{~cm}^{-1}\right)$ and combinations of $\mathrm{C}-\mathrm{H} / \mathrm{C}-\mathrm{C}\left(4385-4063 \mathrm{~cm}^{-1}\right)$ vibrations of the sugar molecules [28].

Accuracy of the generated PLS models was attested by trueness and precision studies. Trueness of multivariate methods is evaluated by RMSECV, RMSEC and RMSEP. All the models presented good correlation between reference values and NIR predicted ones. Fig. 3 shows the correlation between values determined by the reference analysis method and values predicted by the NIR for external validation.
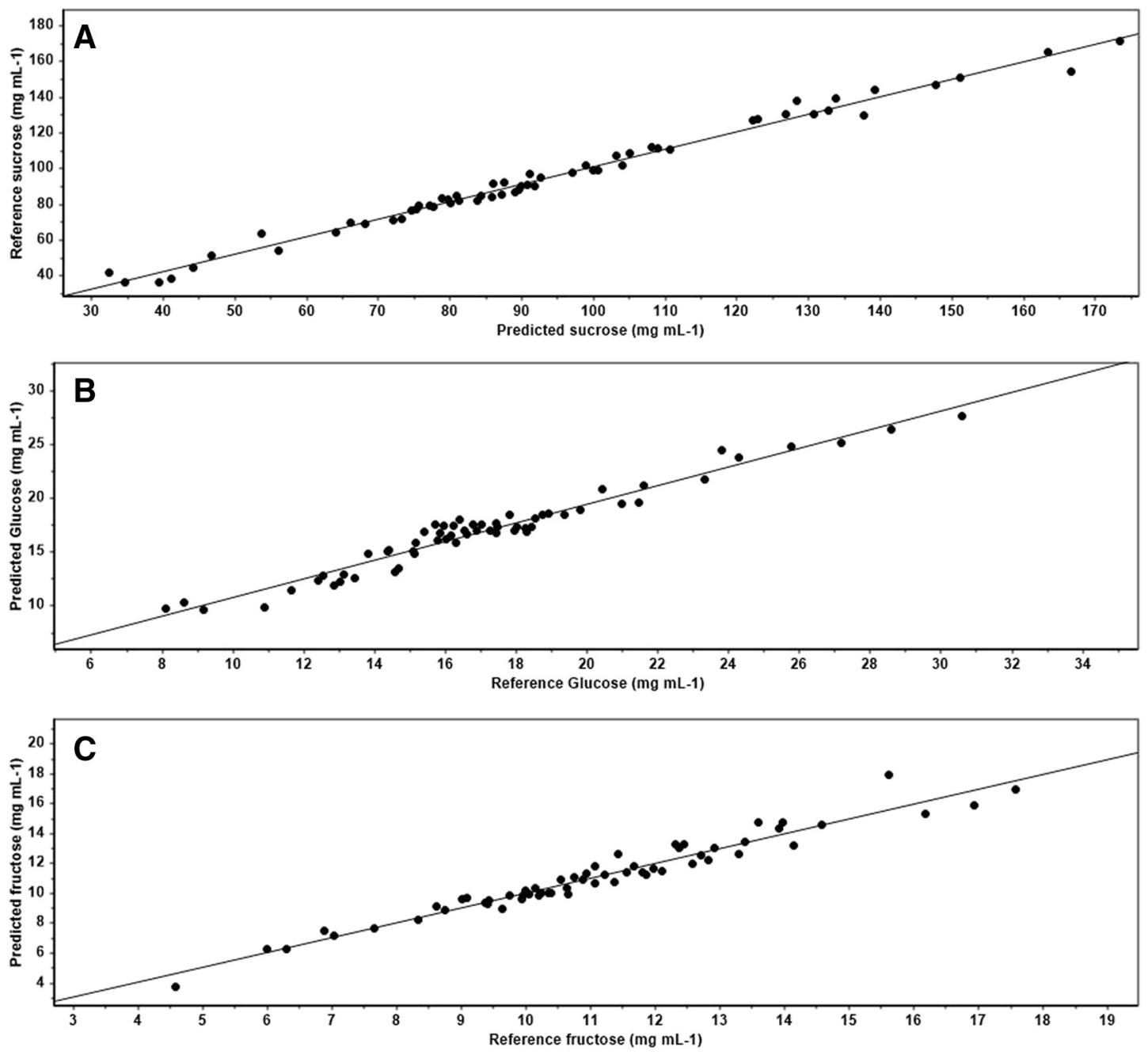

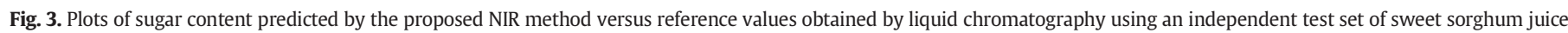
samples. Sucrose (A), glucose (B) and fructose (C). 
A model with five latent variables (LVs) minimized the root mean squared error of cross validation (RMSECV) and maximized $\mathrm{R}^{2}$ for sucrose, or rather RMSECV $=4 \mathrm{mg} \mathrm{mL}^{-1}$ and $\mathrm{R}^{2}=0.99$. A model with eight LVs was selected for glucose, with RMSECV $=1 \mathrm{mg} \mathrm{mL}^{-1}$ and $\mathrm{R}^{2}=0.97$. In the case of fructose, a model with seven LVs showing $\mathrm{RMSECV}=0.6 \mathrm{mg} \mathrm{mL}^{-1}$ and $\mathrm{R}^{2}=0.95$ was selected.

RMSEP expresses the degree of agreement between estimated values by a model previously constructed and a real or reference value [29]. When the predicted values were plotted against the reference values for sucrose, glucose and fructose, the validation samples achieved a root mean squared error of prediction (RMSEP) of 4, 1 and $0.6 \mathrm{mg} \mathrm{mL}^{-1}$, respectively.

The precision was only estimated at the level of repeatability because the sugar content of sweet sorghum juice changes over time and the intermediate precision cannot be evaluated. Consequently, repeatability was evaluated by estimating relative standard deviations (RSD) for triplicates of three sweet sorghum juice samples with low, medium and high sugar contents. RSD varied $0.2,0.3,0.8 \%$ for sucrose; $1,2,2 \%$ for glucose; $1,2,3 \%$ for fructose, respectively. These values can be compared with the expected values issued from the Horwitz eq. [30] and acceptable RSD ( $<4 \%)$ were obtained.

The accuracy of the method was evaluated by the elliptical joint confidence region (EJCR) test, which is frequently used to evaluate accuracy of new analytical methods. This ellipse must contain values of intercept $=0$ and slope $=1$, which indicate the absence of systematic errors [31]. Thus, by taking the critical value for the Snedecor-Fisher statistic at a $95 \%$ confidence level $F_{2,58}=3.15$, we obtain $\beta_{1}<1$ $(0.9768,-1.69,-0.69)$ and $\beta_{2}>1(1.03,3,66,2.69)$ for sucrose, glucose e fructose, respectively. This indicates that the point $(0,1)$ lies inside the EJCR and then, the intercept may be considered to be zero and the slope to be unity, which indicates absence of systematic errors of the PLS method in comparison with HPLC.

RPD and RER ratio relates SEP to variance and range in the original reference data, taking into consideration that RPD should ideally be at least 2.4 and the RER at least 10.0 [21]. Williams and Sobering [32] indicated that the value of 3 or more was recommended. All models in Table 2 presented RPD above 3 and RER above 10 and may be used to screen sweet sorghum genotypes. However, it should be underscored that the accuracy of a model depends on its application and the errors of prediction (RMSEP). By comparison, the prediction of sugars in sweet sorghum juice was consistent with previous reports for dry samples utilizing transmission mode [17, $18,33]$. NIR models may be of great help to breeders to select the sweet sorghum genotypes so that they may have the best sugar profile for bioenergy crop.

\section{Conclusions}

The development of high-throughput screening methodologies is crucial to fast phenotyping in plant breeding. Therefore, we developed a fast an inexpensive method that allowed evaluation of sugar content for sweet sorghum selection for bioenergy purposes. Sugar profile of sweet sorghum juice was determined for sucrose, glucose and fructose by HPLC at different stages during stalk maturation. Using NIR-PLS methods, models were built to determinate sucrose, glucose and fructose present in the juice of sweet sorghum and the results were comparable to those determined by HPLC method. The PLS-NIR method developed is a good alternative to chromatographic methods requiring minimum sample preparation, no chemicals reagents and fast throughput.

\section{Acknowledgements}

The authors are grateful to Fapemig for providing student fellowships and research grants (process number 3013/2014) to Embrapa Maize and Sorghum.

\section{References}

[1] V.F. de Souza, R.A. da C. Parrella, F.D. Tardin, M.R. Costa, G.A. Carvalho Júnior, R.E. Schaffert, Adaptability and stability of sweet sorghum cultivars, Crop Breed. Appl. Biotechnol. 13 (2013) 144-151.

[2] C.M.B. Damasceno, R.E. Schaffert, I. Dweikat, in: M.C. McCann, M.S. Buckeridge, N.C. Carpita (Eds.), Plants and Bioenergy, Springer, New York 2014, pp. 81-106.

[3] F. Jia, J. Chawhuaymak, M.R. Riley, W. Zimmt, K. Ogden, Efficient extraction method to collect sugar from sweet sorghum, J. Biol. Eng. 7 (2013) 1-8.

[4] A.P. Martin, W.M. Palmer, C.S. Byrt, R.T. Furbank, C.P. Grof, A holistic high-throughput screening framework for biofuel feedstock assessment that characterizes variations in soluble sugars and cell wall composition in Sorghum bicolor, Biotechnol. Biofuels 6 (2013) 1-13.

[5] Conselho dos produtores de cana-de-açúcar, açúcar e álcool do estado de São PauloSP (CONSECANA-SP), Normas operacionais de avaliação da qualidade da cana-deaçúcar. 5ª ed., Piracicaba, Available at http://www.orplana.com.br/manual_2006. pdf 2006 (on 03/08/2015).

[6] J.Y. Serpen, Comparison of sugar content in bottled $100 \%$ fruit juice versus extracted juice of fresh fruit, Food Nutr. Sci. 3 (2012) 1509-1513.

[7] H. Kawahigashi, S. Kasuga, H. Okuizumi, S. Hiradate, J. Yonemaru, Evaluation of Brix and sugar content in stem juice from sorghum varieties, Grassl. Sci. 59 (2013) 11-19.

[8] M. Wang, Z. Xin, B. Tonnis, G. Farrell, D. Pinnow, Z. Chen, J. Davis, J. Yu, Y. Hung, G.A. Pederson, Evaluation of sweet sorghum as a feedstock by multiple harvests for sustainable bioenergy production, J. Sustain. Bioenergy Syst. 2 (2012) 122-137.

[9] D.K. Kundiyana, D.D. Bellmer, R.L. Huhnke, M.R. Wilkins, P.L. Claypool, Influence of temperature, $\mathrm{pH}$ and yeast on in-field production of ethanol from unsterilized sweet sorghum juice, Biomass Bioenergy 34 (2010) 1481-1486.

[10] J. Li, S. Li, B. Han, M. Yu, G. Li, Y. Jiang, A novel cost-effective technology to convert sucrose and homocelluloses in sweet sorghum stalks into ethanol, Biotechnol. Biofuels 6 (2013) 174-186.

[11] I. Dolciotti, S. Mambelli, S. Grandi, G. Venturi, Comparison of two sorghum genotypes for sugar and fiber production, Ind. Crop. Prod. 7 (1998) 265-272.

[12] C. Pasquini, Near infrared spectroscopy: fundamentals, practical aspects and analytical applications, J. Braz. Chem. Soc. 14 (2003) 198-219.

[13] B.G. Osborne, Near infrared spectroscopy in food analysis, Encyclopedia of Analytical Chemistry, John Wiley \& Sons, Ltd., 2006

[14] L.E. Rodriguez-Saona, F.S. Fry, M.A. McLaughlin, E.M. Calvey, Rapid analysis of sugars in fruit juices by FT-NIR spectroscopy, Carbohydr. Res. 336 (2001) 63-74.

[15] Y. Roggo, L. Duponchel, J.P. Huvenne, Quality evaluation of sugar beet (Beta vulgaris) by near infrared spectroscopy, J. Agric. Food Chem. 52 (2004) 1055-1061.

[16] A. Salgo, J. Nagy, E. Miko, Application of near infrared spectroscopy in the sugar industry, J. Near Infrared Spectrosc. 6 (1998) 101-106.

[17] S.-F. Chen, M.-G.C. Danao, V. Singh, P.J. Brown, Determining sucrose and glucose levels in dual-purpose sorghum stalks by Fourier transform near infrared (FT-NIR) spectroscopy, J. Sci. Food Agric. 94 (2014) 2569-2576.

[18] F. Xu, L. Zhou, K. Zhang, J. Yu, Rapid determination of both structural polysaccharides and soluble sugars in sorghum biomass using near infrared spectroscopy, Bioenergy Res. 8 (2015) 130-136.

[19] A. May, F.O.M. Durães, I.A. Pereira Filho, R.E. Schaffert, R.A. da C. Parrella, Manejo e tratos culturais. Sistema Embrapa de produção agroindustrial de sorgo sacarino para bioetanol: Sistema BRS1G-Tecnologia Qualidade Embrapa. Sete Lagoas: Embrapa Milho e Sorgo, 2012 22-31.

[20] J. Shenk, M. Westerhaus, Population structuring of near-infrared spectra and modified partial least-squares regression, Crop Sci. 31 (1991) 1548-1555.

[21] R.W. Kennard, L.A. Stone, Computer aided design of experiments, Technometrics 11 (1969) 137-148.

[22] P. Williams, Near infrared technology: in the agricultural and food industries, in: P. Williams, K. Norris (Eds.), American Association of Cereal Chemists, second ed.American Association of Cereal Chemists, St. Paul, Minn., USA 2001, p. 296.

[23] X. Wu, S. Staggenborg, J.L. Propheter, W.L. Rooney, J. Yu, D. Wang, Features of sweet sorghum juice and their performance in ethanol fermentation, Ind. Crop. Prod. 31 (2010) 164-170

[24] F.J. Rambla, S. Garrigues, M. de la Guardia, PLS-NIR determination of total sugar, glucose, fructose and sucrose in aqueous solutions of fruit juices, Anal. Chim. Acta 344 (1997) 41-53.

[25] J.J. Workman Jr., L. Weyer, Practical Guide to Interpretive Near Infrared Spectroscopy, CRC - Press, Boca Raton, USA, 2008.

[26] C.C. Guimarães, C. Assis, M.L.F. Simeone, M.M. Sena, Use of near-infrared spectroscopy, partial least-squares, and ordered predictors selection to predict four quality parameters of sweet sorghum juice used to produce bioethanol, Energy Fuels 30 (2016) 4137-4144.

[27] D.M. Haaland, E.V. Thomas, Partial least-squares methods for spectral analyses. 1. Relation to other quantitative calibration methods and the extraction of qualitative information, Anal. Chem. 60 (1988) 1193-1202.

[28] B.G. Osborne, S. Douglas, Measurement of the degree of starch damage in flour by near infrared reflectance analysis, J. Sci. Food Agric. 32 (1981) 328-332.

[29] W.R. Windham, D.R. Mertens, F.E. Barton, II Protocol for NIRS calibration: Sample selection and equation development and validation, in: C.G. Marten, J.S. Shenk, F.E. Barton (Eds.), Near Infrared Reflectance Spectroscopy (NIRS): Analysis of Forage Quality, 643rd ed.USDA-ARS: Agricultural Handbook, Washington, DC 1989, pp. 96-103.

[30] W. Horwitz, Evaluation of analytical methods used for regulation of foods and drug, Anal. Chem. 54 (1982) 67A-76A.

[31] A.G. González, M.A. Herrador, A.G. Asuero, Intra-laboratory testing of method accuracy from recovery assays, Talanta 48 (1999) 729-736. 
[32] How do we do it: a brief summary of the methods we use in developing near infrared calibrations, in: P.C. Williams, D. Sobering, A.M.C. Daves, P.C. Williams (Eds.), Near Infrared Spectroscopy: The Future Waves, NIR Publications, Chichester, UK 1996, pp. $185-188$.
[33] L. Wu, M. Li, J. Huang, H. Zhang, W. Zou, S. Hu, Y. Li, C. Fan, R. Zhang, H. Jing, L. Peng, S. Feng, A near infrared spectroscopic assay for stalk soluble sugars, bagasse enzymatic saccharification and wall polymers in sweet sorghum, Bioresour. Technol. (2015) $118-124$ 